\title{
Clinical skills required of ophthalmic nurse practitioners in tertiary level public hospitals in the Western Cape Province
}

\author{
U Kyriacos, MSc (Nursing) (UCT) \\ Senior Lecturer, Division of Nursing and Midwifery, University of Cape Town \\ LD Scheepers, Postgraduate Diploma in Nursing (UCT), RN, RM \\ Chief Professional Nurse, Eye Clinic, Eerste Rivier Hospital, Cape Town
}

EW Hill, Postgraduate Diploma in Nursing (UCT), RN, RM.

Chief Professional Nurse, Eye Outpatient Department, Groote Schuur Hospital, Observatory, Cape Town

S Jordan, MB.BCh., PhD., PGCE (FE).,

Reader, School of Health Science, Swansea University, Wales, United Kingdom

\section{Kev words}

ophthalmic nurse practitioners; clinical skills; post-registration/continuing education; expanded roles; tertiary level nursing care.

\section{Correspondence address}

UKyriacos

Faculty of Health Sciences

School of Health \& Rehabilitation

Sciences

Division of Nursing \& Midwifery

Old Main Building

Groote Schuur Hospital

Observatory 7925

\section{Telephone: (021) 406-6401}

Fax: (021) 406-6323

E-mail : una.kyriacos@uct.ac.za

\section{Abstract: Curationis 32 (3): 22-29}

Background: South Africa has a 32-year history of training ophthalmic nurse practitioners (ONPS). The role and required skills and competencies of ONPs are not well documented in the international literature and are also absent from South African publications, including South African Nursing Council publications.

Aim: This study aims to inform curriculum development and human resource planning by reporting on the clinical skills expected of ONPs by members of multidisciplinary ophthalmology teams.

Method: A limited survey was undertaken in the ophthalmology wards and outpatient departments of three tertiary level hospitals in the Western Cape Province. A researcher-designed structured self-completion questionnaire was distributed to 30 ophthalmology practitioners: doctors, nurses and technicians. Respondents were asked to indicate the expected clinical skills of ONPs.

Findings: All questionnaires were completed. All respondents favoured ONPs taking histories and performing emergency eye irrigations. There was less support for more complex procedures, such as B-scans. One-third of respondents did not expect ONPS to have skills in eight key areas, including examination of the anterior chamber angle for glaucoma. No statistically significant differences were found between responses of doctors and nurses, with one exception: more nurses (15/18) than doctors (4/10) had confidence in the ONP undertaking basic eye examinations for ocular motility (Fisher's exact test, $P=0.035$ ).

Conclusion: In the study settings, ONPs are not using their specialist skills to the full. Not all practitioners were receptive to ONPs using the skills that they had acquired during their postgraduate diploma, threatening the educational effectiveness of this initiative. 


\section{Background}

The key role of ophthalmic nurse practitioners (ONPs), in its broadest sense, is prevention of avoidable blindness. Seventy-five per cent of the blindness in the world is either preventable or avoidable (World Health Organization (WHO), 2006: 1). Avoidable blindness, some of which could be corrected with spectacles, results in dependency for basic activities of daily living and loss of income, dignity and self-worth.

A global initiative launched in 1999, 'VISION 2020: the Right to Sight', is a partnership between the WHO and the International Agency for the Prevention of Blindness; its ultimate goal is integration of sustainable, comprehensive, high-quality, equitable eye care systems into strengthened national health-care systems (WHO, 2007: v). The commonest causes of blindness globally are cataracts and glaucoma (Thomas \& Parikh, 2006: 36). It is recommended that, to prevent blindness due to these conditions in South Africa, 40 district level VISION 2020 programmes should be implemented. Each should serve one million people and perform 2000 - 4000 cataract operations a year, and should be located within eye surgical units in district hospitals at secondary level care, to allow tertiary level hospitals to provide specialist eye care services (Cook \& Qureshi, 2005: 87).

In the Western Cape trained voluntary community eye care workers do basic eye screening and refer clients with a visual acuity $(V A)$ of $6 / 12$ improved with a pinhole test to optometrists; those with a VA of 6/12 not improved by pinhole or who have any abnormality are referred to clinical nurse practitioners. If clinical nurse practitioners cannot treat such patients they are referred to ONPs in selected secondary health care settings; the ONPs are trained to manage a range of eye conditions and to make appropriate referrals of patients to ophthalmologists in secondary and tertiary level hospitals. Currently the majority of ONPs work in tertiary level hospitals. Eye technicians in these specialist centres perform diagnostic investigations using sophisticated technology.

In 2000 there were only 275 ophthal- mologists on the register of the Health Professions Council of South Africa, serving a population of 40 million people. Of these ophthalmologists, 250 worked in the private sector serving 8 million people and only 25 worked in the government sector serving $32 \mathrm{mil}$ lion (WHO press release, 2000), falling far short of the target of 1 tertiary care specialist per million population advocated by Cook \& Qureshi. (2005: 87). If effective eye health services are to be provided and sustained, the present complement of eye health professionals is insufficient to meet the needs of the population.

Post-registration ophthalmic nursing programmes in the Western Cape were discontinued in 1988; this has caused a serious shortage of ONPs and may have contributed to lack of knowledge of the role of the ONP. In 2008 there were 346 ONPs $(0.33 \%$ of all registered nurses (RNs)) on the register of the South African Nursing Council (SANC) and 35 certificated ONPs (Personal communication by e-mail, SANC, II February 2009), but these practitioners are nearing retirement. Although there is an urgent need for ONP specialist skills in the public health sector, the National Department of Health's (DoH) Human Resources Health Plan for South Africa (2006) is silent on the number of nursing specialisations that need to be developed to meet the demands of the health system. Nevertheless, the Provincial DoH has committed itself to the aims of VISION $2020 \mathrm{by}$ providing bursaries and full-time study leave to RNs for ophthalmic nursing studies (Personal communication: Powell, Project Manager, Eye Care Services, Metro District Health Services, 2006).

For this programme to succeed, one ONP is needed at each primary care clinic or community health centre. In addition, one ONP per 100000 members of the population is needed at secondary level, as well as one ophthalmologist (eye care specialist) and other ophthalmic-trained personnel per one million population at tertiary level. Twenty-seven ONPs are needed in the Health Department of the Western Cape (Personal communication: Powell. 2006). This means an additional 10 ONPs will have to be trained within the next five years. Accordingly, in 2005 the
University of Cape Town introduced an elective pathway in Ophthalmic Nursing within the Postgraduate Diploma in Nursing to meet this need. Successful completion of this diploma allows the nurse to practice as an ONP.

Introduction of ONPs has proved costeffective, and has not compromised quality of patient care (Banerjee, Beatty, Tyagi \& Kirkby, 1998: 880). Rather, the continuous presence of ONPs in ophthalmologv departments facilitates delivery of specialised nursing care (Waterman \& Waterman 1999: 948). ONPs fulfill an important role in the management of emergencies and selfreferring patients, and their introduction increases throughput of patients, allowing doctors to devote more time to complex cases and referrals from general practitioners (Ilango, McGalliard \& Hughes, 2000: 45).

The UK competency framework for ophthalmic nursing (RCN, 2005 approved by the RCN Accreditation Unit until 31 July 2009) and scope of practice for ONP-led clinics in Australia (Kirkwood, Coster \& Essex, 2006: 173, Kirkwood, Pesudovs, Loh \& Coster, 2005: 593) provide clear role definitions and competencies. However, evidence that South African ONPs use their skills is limited, and their roles are undefined. ONPs are integral to specialist teams; however, their role needs to be clarified, particularly in specialist, tertiary level referral hospitals. The clinical skills required of the ONP in tertian level hospitals is the focus of this paper.

\section{Problem}

The scope of specialist skills required of the ONP in public tertiary level hospitals in the Western Cape has not been described. The diploma qualifies ONPs to do VA assessment, take an ophthalmic history and perform a dilated eye examination in addition to the management of certain chronic and emergency eye conditions, and making effective referrals. However, it is uncertain whether ONPs have the opportunity to work at this level in tertiary level hospitals. This raises questions about the inappropriate use of highly trained ONPs who should be working alongside ophthalmologists and eye technicians in tertiary level specialist hospi- 
tals.

\section{Aim}

The study aimed to describe the range of skills gained in an ONP postgraduate programme, and to explore the perceptions of relevant health professionals concerning the skills required of ONPs.

\section{Design}

In the nascent field of educational effectiveness evaluation, the 'case study' offers a degree of flexibility in the selection of research approaches (Yin 2003). For this descriptive survey a selfadministered structured questionnaire with open and closed questions in English and Afrikaans was completed by ophthalmology practitioners to explore their perceptions of the scope of clinical skills required of the ONP. Self-administered questionnaires allow the opinions of a large number of respondents to be processed anonymously, and without bias incurred by introduction of an interviewer (Polit \& Beck, 2008). They are therefore well suited to establishing the prevalence of perceived problems with the curriculum (McNeill, 1990; Jordan, Coleman, Hardy \& Hughes, 1999; Boynton, 2004). Our questionnaire was designed to elicit a mix of basic quantitative information and qualitative data from one openended question.

\section{Participants and setting}

The research setting comprised three tertiary level hospitals in the Western Cape that had only four ONPs between them; one hospital is the only specialist paediatric hospital in the sub-Saharan region, and it had one ONP. The hospitals had a total bed capacity of about 2398; one of the hospitals, for which figures are available, had an annual ophthalmology outpatient attendance of approximately 21258.

Purposive sampling took place of all ONPs, RNs, area nurse managers, ophthalmologists, registrars and eye technicians in the eye wards and outpatient departments of the three hospitals who were on duty during one particular working week and were willing to participate. The sample comprised: four ONPs, nine RNs, five nurse managers, five ophthalmologists, five ophthalmol- ogy registrars and two ophthalmic technicians $(N=30)$. The skills mix of these respondents is typical of the ophthalmology professionals in the hospitals.

\section{Method}

The questionnaire was tailored to be of interest to potential respondents (Dillman, 2007) by listing all clinical skills taught on the ONP postgraduate diploma programme plus removal of corneal rust ring, using the $B$-scan and Humphrey Field analyser, and prescription of medication, and asked respondents whether these were necessary for an ONP in a tertiary-level public hospital. The questionnaire was examined by an ophthalmologist and an ophthalmic nurse outside the study sample for factual accuracy, expert validation and face validity (Polit \& Beck, 2008). It was then cognitively tested and piloted with four $R N s$ working on wards not included in the study; investigators asked for comments, specifically, comprehension, interpretation and ease of completion (Campanelli 2008), but not for factual accuracy since this had been seen to by the subject experts. No problems were encountered with the questionnaire.

To ensure anonymity and confidentiality, respondents were asked to participate voluntarily and to return completed questionnaires via sealed boxes placed prominently in outpatient departments and eye wards. Ethical approval for the study was obtained from the University of Cape Town Research Ethics Committee, after which consent was obtained from each of the hospital governance structures. All data were rendered anonymous. Return of the questionnaires was taken to indicate consent to participate in the study and to use the data.

\section{Data analysis}

Data were entered into Excel spreadsheets and analysed using the statistical package for the social sciences (SPSS Inc., Chicago, Il., USA) for Windows, version 14. Data were described with frequencies and percentages. Perceptions of doctors and nurses were compared using two-way contingency tables and Fisher's exact test (Field, 2009). The two technicians were excluded from this analysis, leav- ing 28 respondents. The small sample size precluded further analysis. To achieve a measure of consensus to guide curriculum development (UCT, 2005), clinical skills expected of the ONP by fewer than $70 \%$ (20/28) of doctors and nurses were highlighted.

\section{Results}

The skills considered are listed in Table 1. All respondents agreed that ONPs should be able to take histories, use a Snellen chart, irrigate an eye, insert or remove an ocular prosthesis, teach patients and manage chemical burns.

Data show that there was general agreement between nurses and doctors regarding competencies required of the ONP. A statistically significant association ( $P=0.035$ ) was found between profession and basic eye examination of ocular motility, with nurses showing more confidence in the ONP than doctors. Some differences were apparent when subgroups of professionals were examined. While all five ophthalmologists thought that the ONP should examine the posterior segment of the retina, optic disc and macula, this was true for only one, four and two of the five registrars respectively. ONPs were cautious with regard to examination of the optic disc and macula (2/4 in agreement), but less so for examination of the retina (3/4). Surprisingly, only two of the four ONPs were in favour of ONPs examining the red reflex.

All ONPs agreed that they should prescribe certain eye medication, as did four of the five ophthalmologists, three of the five registrars and the nurse managers. Whereas all ophthalmologists and RNs thought that the ONP should undertake telephone triage, two of the five registrars and nurse managers and one ONP disagreed. While ophthalmologists and ONPs agreed that ONPs should use all eye-test charts, a few (1) 5) registrars and nurse managers and RNs (2/9) did not agree with ONPs using the Sheridan Gardner chart or the E-chart. The eye technicians were not supportive of the ONP performing much more than history taking, basic eye examination of eyelids, $V A$ testing, emergency eye irrigation, patient education, basic eye examination of external structures and patient education. 
Table 1. Doctors' and nurses' perceptions of clinical skills required of the ONP (data from two eye technicians excluded)

No. (\%) stating skill required

\begin{tabular}{|c|c|c|c|}
\hline Clinical skills required & $\operatorname{Doctors}(N=10)$ & $\operatorname{Nurses}(N=18)$ & $P^{*}$ \\
\hline History taking & $10(100)$ & $18(100)$ & $N A$ \\
\hline Snellen chart VA testing & $10(100)$ & $18(100)$ & $N A$ \\
\hline Emergency eye care: eye irrigation & $10(100)$ & $18(100)$ & $N A$ \\
\hline Insertion and removal of an ocular prosthesis & $10(100)$ & $18(100)$ & $N A$ \\
\hline Patient education & $10(100)$ & $18(100)$ & $N A$ \\
\hline Management of emergency eye irrigation after chemical burn & $10(100)$ & $18(100)$ & $N A$ \\
\hline Basic eye examination of conjunctiva & $9(90)$ & $17(94.4)$ & 1.00 \\
\hline Basic eye examination of sclera & $10(100)$ & $17(94.4)$ & 1.00 \\
\hline Basic eye examination of cornea & $10(100)$ & $16(88.9)$ & 0.53 \\
\hline Basic eye examination of pupil & $9(90)$ & $16(88.9)$ & 1.00 \\
\hline Basic eye examination of anterior chamber angle & $5(50)$ & $15(83.3)$ & 0.09 \\
\hline Basic eye examination of ocular motility & $4(40)$ & $15(83.3)$ & $0.035^{* *}$ \\
\hline Basic eye examination of red reflex & $10(100)$ & $14(77.8)$ & 0.27 \\
\hline Slit lamp examination of cornea & $9(90)$ & $15(83.3)$ & 1.00 \\
\hline Slit lamp examination of corneal staining & $9(90)$ & $13(72.2)$ & 0.38 \\
\hline Slit lamp examination of lens & $8(80)$ & $13(72.2)$ & 1.00 \\
\hline Slit lamp examination of anterior chamber & $5(50)$ & $13(72.2)$ & 0.41 \\
\hline Slit lamp examination of iris & $7(70)$ & $12(66.7)$ & 1.00 \\
\hline IOP measurement by tonopen & $10(100)$ & $12(66.7)$ & 0.06 \\
\hline IOP measurement by Goldmann applanation tonometer & $7(70)$ & $13(72.2)$ & 1.00 \\
\hline Sheridan Gardner VA testing & $9(90)$ & $15(83.3)$ & 1.00 \\
\hline E-Chart VA testing & $10(100)$ & $15(83.3)$ & 0.53 \\
\hline Ophthalmoscopic examination of retina & $6(60)$ & $15(83.3)$ & 0.20 \\
\hline Ophthalmoscopic examination of optic disc & $9(90)$ & $14(77.8)$ & 0.63 \\
\hline Ophthalmoscopic examination of macula & $7(70)$ & $14(77.8)$ & 0.67 \\
\hline Incision and curettage of chalazion & $10(100)$ & $15(83.3)$ & 0.53 \\
\hline Probing and syringing lacrimal duct & $5(50)$ & $12(66.7)$ & 0.44 \\
\hline Management of emergency removal of superficial foreign body on cornea & $9(90)$ & $17(94.4)$ & 1.00 \\
\hline Management of emergency removal of corneal rust ring \# & $4(40)$ & $9(50)$ & 0.71 \\
\hline Use diagnostic B-Scan \# & $3(30)$ & $9(50)$ & 0.43 \\
\hline Use diagnostic Humphrey Field Analyser \# & $7(70)$ & $10(55.6)$ & 0.69 \\
\hline Rehabilitation of the blind/visually impaired & $8(80)$ & $15(83.3)$ & 1.00 \\
\hline Take a conjunctival swab & $10(100)$ & $17(94.4)$ & 1.00 \\
\hline Epilation & $10(100)$ & $13(72.2)$ & 0.13 \\
\hline Dry eve test & $9(90)$ & $17(94.4)$ & 1.00 \\
\hline Insert/remove prosthesis & $10(100)$ & $16(88.9)$ & 0.52 \\
\hline Insert/remove contact lens & $9(90)$ & $17(94.4)$ & 1.00 \\
\hline Remove eyelid skin sutures & $10(100)$ & $16(88.9)$ & 0.52 \\
\hline Prescribing certain eye medication & $7(70)$ & $14(77.8)$ & 0.67 \\
\hline Telephonic triage & $8(80)$ & $15(83.3)$ & 1.00 \\
\hline
\end{tabular}




\section{Table 2. Additional comments about expected clinical skills of the ONP}

should dilate pupils

Examination of the posterior segment should only be used for screening purposes and not for detailed diagnoses

... should know how to suture eyelid lacerations that did not involve the lid margin

... should be able to screen children for a squint

... should have knowledge of low-vision aids and also know how to treat presbyopia in the normal individual

... should know how to use the auto refractor, keratometer and know how to do an A-scan for lens strength

Emergency eye care should only be performed in the ward after hours (after 16h00)

In response to the only open-ended question, participants provided additional information about skills required of the ONP (Table 2).

Clinical skills expected of the ONP by fewer than $70 \%(20 / 28)$ of doctors and nurses (taken to indicate less perceived relevance of these skills) are listed in Table 3. These include examination of the anterior chamber angle, which is an important aspect of screening for glaucoma. Only $40 \%$ (2/5) of the ophthalmologists, $60 \%(3 / 5)$ of the registrars, $77.8 \%(7 / 9)$ of the RNs and $75 \%(3 / 4)$ of the ONPs - but all of the nurse managers - were in favour of ONPs performing this task. Fewer registrars than ophthalmologists were in favour of ONPS examining the anterior chamber $(2 / 5 v s$. $3 / 5)$ and the iris (3/5vs. 4/5), and only half (2/4) of the ONPs thought that the ONP should examine the anterior chamber and the iris.

\section{Discussion}

Some but not all of the specialised ophthalmic nursing skills provided by the postgraduate diploma are used in tertiary hospitals. Eight competencies (Table 3) were not considered appropriate for the ONP by $29 \%$ or more respondents.

No statistically significant association was found between responses and professions, with the single exception of more nurses than doctors having con- fidence in the ONP doing a basic eye examination for ocular motility. Due to the number of comparisons made, we cannot exclude the possibility that this association arose by chance. Overall, registrars, nurse managers and technicians expressed more caution over the ONPs' role than did ophthalmologists and ONPs. Registrars do not routinely observe ONPs using ophthalmic nursing skills, and this may have accounted for their narrow perspective of the ONPs' required clinical skills.

Items where consensus was achieved centred on history taking, VA using a Snellen chart, patient education and emergency care. History taking and patient education depend on communication skills, which are essential components of good practice (Connolly \& Hosker, 200I). In retrospect, communication skills should have been added to the list of clinical skills, since these are evaluated in the programme (but in a separate module). Ophthalmologists are interrupted by constant phone calls. If ONPs manage telephone triage (82\% supported this), everyone benefits, since waiting times will be reduced, general practitioners ' referrals will be facilitated, and doctors' time will be better used. This may account for the ophthalmologists' endorsement of this aspect of the ONP role.

Overall, there is some evidence that ophthalmic nursing skills could be more effectively deployed to relieve ophthalmologists of basic examinations and improve efficiency of services. Failure to do so may act as barriers to role ex-

Table 3. Clinical skills not supported by $29 \%$ or more respondents ( $N=28$ )

\begin{tabular}{|l|c|c|}
\hline Competency & Numbers not supporting /28 & \% not supporting \\
\hline Use diagnostic B-Scan & 16 & 57.14 \\
\hline Management of emergency removal of corneal rust ring & 15 & 53.57 \\
\hline Probing and syringing lacrimal duct & 11 & 39.27 \\
\hline Do eye fields with Humphrey field testing machine & 11 & 39.27 \\
\hline Slit lamp examination of anterior chamber & 10 & 35.71 \\
\hline Basic eye examination of ocular motility & 9 & 32.14 \\
\hline Slit lamp examination of iris & 9 & 32.14 \\
\hline Basic eye examination of anterior chamber angle & 9 & 32.14 \\
\hline
\end{tabular}


pansion and prevent newly acquired knowledge being used for the benefit of patients (Jordan \& Hughes, 1998: 1065). For example, there was opposition to ONPs syringing the lacrimal duct, examining the anterior chamber with a slit lamp and using some vision testing charts. The participants resistant to the suggestion of ophthalmic nurses probing and syringing the lacrimal duct were the doctors $(2 / 5$ ophthalmologists; $3 / 5$ registrars) and nonspecialist nurses (3/9 RNs; 2/5 managers).

There was caution regarding examination of the anterior chamber angle with a slit lamp. More doctors favour ONP examination of the cornea with corneal staining, and of the lens and iris, than favour examination of the anterior chamber with the slit lamp. This is prudent, although it may have implications for screening for glaucoma which, it is estimated, accounts for $14 \%$ of blindness in South Africa (www.who.int/intpr-2000/en/pr2000-27.html). As Bowman and Kirupananthan (2006: 38) state: "Finding the patient while there is still some useful vision to save is one of the major challenges in the management of glaucoma in Africa." These authors recommend population-based $V A$ screening for referral for cataracts as an opportunity for ophthalmologists to check for glaucoma. Buchan, Saihan and Reynolds (2003: 226) in the UK found that "with appropriate threshold for referral, nurses trained in slit lamp examination can offer a successful service to safely diagnose and treat common eye casualty presentations". A concern of one ophthalmologist was that slit lamps will not always be available, and the ONP should learn how to examine the anterior segment with a torch. Our respondents were more likely to favour tonopens and tonometers for glaucoma screening, perhaps because the slit lamp is a complex instrument and time and skill are needed to use it with confidence. In contrast, the tonopen is an easy-to-use, battery-operated, portable applanation tonometer. but not all clinics have these, and a normal intra-ocular pressure does not preclude glaucoma.

The Sheridan Gardner chart is used to test young children's vision and the Echart is used to test the VA of illiterate persons. In view of the large number of illiterate patients attending public hospitals, it is surprising that anyone considered these unnecessary. The reluctance of ONPS to test the red reflex has serious implications for cataract screening

Eye examination is a core skill taught during the postgraduate diploma. However, it takes time and practice to master the skill of fundoscopy examination with an ophthalmoscope, especially in a patient with undilated pupils, which may account for the caution expressed by respondents. Results of fundoscopy examinations by the ONPs differ from ophthalmologists' assessments of retinal photographs in $4 \%$ of cases (Connolly \& Hosker, 2001), and one reason is poor dilation of pupils. However, emergency nurses are more accurate in examining and describing anatomical structures such as the cornea, conjunctiva and iris than doctors (Ezra, Mellington, Cugnoni \& Westcott, 2005).

All RNs in ophthalmology departments (non-trained) are expected to perform eye irrigations in emergencies, to prevent blindness; accordingly, all ophthalmology practitioners agreed that ONPs should irrigate eyes to manage chemical burns. All ophthalmologists, ONPs and RNs said that the ophthalmic nurse should remove superficial foreign bodies from the cornea, but not all registrars and nurse managers agreed. The lowest agreement related to removal of corneal rust rings. The reason for caution could be that the procedure has to be done with a special instrument (burr) that vibrates and can injure the cornea. The willingness to pass emergency care to ONPs was echoed in the comment that ONPs should only provide emergency eye care 'after hours'. However, patients are entitled to the same standard of care at any time, and any implication of double standards is cause for concern. $\mathrm{Pa}$ tients ' rights are enshrined in Chapter 2 of the Constitution of South Africa (Act 108 of 1996) (hitp:// n'ww'info.gov.za/documents/constitution/19.96/index.htm). the Batho Pele principles (n'w'w.dpsa.gov.za/bathopele). and the Patients Rights Charter (ww' doh gov.za/docs/legislation/ patientsright/chartere html).

There was uncertainty about the prescription of certain eye medications, possibly because a special qualification is needed (SANC Regulations Relating to the Keeping, Supply, Administering or Prescribing of Medicines by nurses, Government Notice No. R.2418, 2 November 1984) to prescribe any medication. This qualification is not embedded in the ONP postgraduate diploma at present.

\section{Limitations of the study}

As with all surveys, we have no indication as to the durability of the views expressed-particularly the reason that technicians (and to some extent registrars) expressed overt caution in terms of the skills required of ONPs in tertiary care settings. Our findings concern a unique course, conducted in a single geographical location and in specialised departments, with few participants over a short period of time. The survey was limited to clinical skills required of ONPs, but this is only a small portion of a more comprehensive role and scope of practice for such specialised practice. Studies on single cohorts or 'cases' form the units of education research (Simons, 1980: 7; Clammer, 1984: 67); the inferences drawn from such studies are logical rather than statistical (Mitchell, 1983: 193). We suggest that ourfindings have sufficient 'practical adequacy' and contextual richness to guide further developments of expanded nursing roles (Sayer, 1992: 65).

\section{implications and Recommendations}

This study has implications for policy directives for a competency framework for ophthalmic nursing, the ONPs' role in preventing avoidable blindness, and education-practice links

\section{Policy directives for a competency framework for ONPS}

There appears to be no clear understanding of the clinical skills required of ONPs in tertiary health care facilities in the Western Cape, and this may be the case in other provinces. Practice changes are facilitated by policy directives. A national competency framework for ophthalmic nursing is needed to carve an expanded role for ONPs, and to standardise practice in tertian, secondany and primary health care facilities within the Health Care Plan for 
South Africa. Ophthalmic nurses themselves, in consultation with ophthalmologists and the Provincial and $\mathrm{Na}$ tional DoH, are best placed to take this forward.

\section{Education-practice links}

Limited understanding of the clinical skills required of ONPs in tertiary health care facilities results in inefficient use of highly skilled nurses, ultimately to the detriment of patients with sightthreatening conditions. More work is needed to ensure that nurse educators collaborate with each other at a national level and with all eye care practitioners to jointly plan comprehensive, relevant curricula to ensure that ONPs' skills are transferable, irrespective of geographical location. This collaboration is also essential to ensure that ONPs' skills are optimised to improve quality of care, increase the number of patients seen, shorten waiting times and relieve ophthalmologists of basic eye examinations. However, they need continuing education for 're-skilling' and 'upskilling'.

If, on completion of postgraduate programmes, nurses are unable to fulfill their expanded roles and practise their newly acquired skills, these skills may fall into disuse, rather than being consolidated in a period of preceptorship. Those best placed to act as preceptors to new ONP graduates are ophthalmologists and registrars; it is therefore disappointing that in some instances their view of ONPS' competencies was limited.

\section{ONPs' role in preserving vision and meeting targets}

This small study raises questions about the appropriateness of the presence of ophthalmic nurses in tertiary level outpatient departments if their skills are underutilised. Should they rather be redeployed to primary and secondary (district) level health care settings characterised by a critical shortage of ophthalmologists - where their specialist skills are needed for management of certain chronic and emergency eye conditions and effective referrals?

By skilful and timely actions, ONPs can play important roles in preserving vision. Human resources are needed to meet the ultimate goal of VISION 2020 . integration of sustainable, comprehen- sive, high-quality, equitable eye care systems into strengthened national health care systems. To meet targets for primary-and secondary level health sector staffing, specific human resource training needs should be established for 5-year cycles to make provision for retiring ONPs.

\section{Conclusion}

Where health care resources are limited, enhancing and expanding nursing roles is the strategy most likely to improve delivery of universal care. However, there may be barriers to the realisation of such goals and policy initiatives. Role expansion requires change and development in both education and practice.

To maximise the educational effectiveness of postgraduate nursing programmes, the teaching of competencies should not be undertaken in isolation. The goals of nurse education initiatives are more likely to be achieved if entrenched attitudes in the workplace can be modified, to ensure that the clinical environment is receptive to expanded nursing roles and nurse practitioners assuming new responsibilities that were formerly the preserve of doctors.

\section{References}

BANERJEE,S; BEATTY,S; TYAGI, A \& KIRKBY, GR 1998: The role of ophthalmic triage and the nurse practitioner in an eye-dedicated casualty department. Eve 12:880-882.

BATHO PELE PRINCIPLES. www.dpsa.gov.za/batho-pele/ Principles.asp. Accessed 17 August 2009.

BOWMAN, RJC \& KIRUPANANTHAN, S 2006: How to manage a patient with glaucoma in Africa. Community Eve Health Journal. 19(59): 38-9, September.

BOYNTON, P 2004: Administering, analysing and reporting your questionnaire. BMJ. 328: 1372-5.

BUCHAN, JC; SAIHAN, Z \& REYNOLDS, AG 2603: Nurse triage, diagnosis and treatment of eye casualty patients: a study of quality and utility. Accident and Emergency Nursing. 11(4): 226-8, October.
CAMPANELLI, P 2008: Testing Survey Questions. In: Hox, J; de Leeuw, E \& Dillman, D, eds. International Handbook of Survey Methodology.

CLAMMER, R 1984: Approaches to ethnographic research. In: ELLEN, $R$, ed. Ethnographic Research. London, Academic Press. pp. 63-85.

CONNOLLY, A \& HOSKER, C 2001: The nurse's role in screening for diabetic retinopathy. Nursing Times. 97(13): 40-41.

SOUTH AFRICA (REPUBLIC): Constitution of South Africa (Act 108 of 1996), http://www.info.gov.za/documents/constitution/1996/index.htm. Accessed 17 August 2009.

COOK, C \& QURESHI, B 2005: VISION 2020 at the district level. Communitv Eve Health Journal. 15(54): 85-87.

SOUTH AFRICA (REPUBLIC) 2006: Department of Health South Africa 2006. A National Human Resources for Health Planning Framework. Pretoria: Government Printer.

DILLMAN, D 2007: Mail and Internet Surveys: the tailored design method. New York: Wiley.

EZRA, DG; MELLINGTON, F; CUGNONI, H\& WESTCOTT,M 2005: Reliability of ophthalmic accident and emergency referrals: a new role for the emergency nurse practitioner? Emergencv Medical Journal. 22(10): 696-699.

FIELD, A 2009: Discovering statistics using SPSS. $3^{\text {rd }}$ edition. London: Sage.

HARDWICK, S \& JORDAN, S 2002: The Impact of Part-Time, Post-Registration Degrees on Clinical Practice. Journal of Advanced Nursing. 38(5): 524-35.

ILANGO, B; MCGALLIARD, JN \& HUGHES, A 2000: The role of nurse practitioners in a primary care eve clinic. Accident and Emergency Nursing $8(1): 42-45$.

JOHNSON, GJ 1992: Global perspective on blindness. Oxford Textbook of Ophthalmology, Volume 2, Section 2.43.24:953-957. Oxford University Press. 
JORDAN, S; COLEMAN, M; HARDY, B \& HUGHES, D 1999: Assessing educational effectiveness: the impact of a specialist course on the delivery of care. Journal of Advanced Nursing. 30(4): 796-807.

JORDAN, S \& HUGHES, D 1998: $U s$ ing Bioscience knowledge in nursing: actions, interactions and reactions. Journal of Advanced Nursing. 27(5): 1060-8.

KIRKWOOD, BJ; COSTER, DJ \& ESSEX, RW 2006: Ophthalmic nurse practitioner led diabetic retinopathy screening. Results of a 3-month trial, Eve. 20(2):173-177, February

KIRKWOOD, BJ; PESUDOVS, K; LOH, RS \& COSTER, DJ 2005: Implementation and evaluation of an ophthalmic nurse practitioner emergency eye unit. Clinical and Experimental Ophthalmologv. 33: 593-597.

MCNEILL, P 1990: Research Methods. (2nd edition). London: Routledge.

MITCHELL, JC 1983: Case and situation analysis. Sociogical Review. 31(2): 187-211.

\section{PERSONAL COMMUNICATION:}

Green, A. Executive Manager: Information Management, South African Nursing Council, II February 2009.

PERSONAL COMMUNICATION: Powell, D. Project Manager, Eye Care Services, Metro District Health Services, 2006).

POLIT, DF \& BECK, C 2008: Nursing Research: Generating and Assessing Evidence for Nursing Practice. $\left(8^{\text {th }}\right.$ Edition). Philadelphia: Lippincott.

\section{ROYAL COLLEGE OF NURSING}

2009: RCN Competencies: an integrated career and competency framework for ophthalmic nursing, London: $R C N$.

SAYER, A 1992: Method in Social Science. London: Routledge.

SIMONS, H 1980: Towards a Science of the Singular. Norwich, Centre for Applied Research. Occasional publication No.10. Norwich: University of East Anglia.
SOUTH AFRICAN NURSINGCOUNCIL 1984: Regulations Relating to the Keeping, Supply, Administering or Prescribing of Medicines by Registered Nurses, Government Notice No. R. 2418, 2 November.

SOUTH AFRICA (REPUBLIC) UNDATED: The Patients Rights Charter. www.doh.gov.za/docs/legislation/ patientsright/chartere.html. Accessed 17 August 2009.

THOMAS, R \& PARIKH, RS 2006: Communitv Eve Health Journal. 19(59). 36-7 September.

UNIVERSITY OF CAPE TOWN 2008: Postgraduate Diploma in Nursing curriculum: Ophthalmic Nursing. KYRIACOS, U. Unpublished.

WATERMAN, E; WATERMAN, H 1999: Trends in ophthalmology services, nursing skill mix and education: $2^{\text {nd }}$ national survey. Journal of Advanced Nursing. 30(4): 942-949.

WORLDHEALTHORGANIZATION 2006: 59th World Health Assembly, A59/12, 24 April. Prevention of avoidable blindness and visual impairment, Report by the Secretariat http:// www.vision $2020 . n \mathrm{l} / \mathrm{contents/}$ WHA5912.pdf Accessed 17 August 2009.

WORLD HEALTHORGANIZATION 2007: VISION 2020 The Right to Sight Global Initiative for the elimination of avoidable blindness Action plan 20062011. http://www. who.int/blindness/ Vision 2020\%20-report.pdf. Accessed 17 August 2009.

WORLD HEALTHORGANIZATION 2000: WHO/27 Press Release 19 April. Global initiative for the elimination of avoidable blindness Vision 2020 launched in English speaking Africa, South Africa set to eliminate cataract blindness within the next five years.

YIN, R 2003: Case Study Research: Design and Methods. Applied Social Research Methods Series, Volume 5. California: Sage, Thousand Oaks. 